This is an electronic reprint of the original article. This reprint may differ from the original in pagination and typographic detail.

Author(s): Dzolic, Zoran; Beyeh, Ngong Kodiah; Cetina, Mario; Turunen, Lotta; Rissanen, Kari

Title: $\quad$ Self-Complementary Dimers of Oxalamide-Functionalized Resorcinarene Tetrabenzoxazines

Year: $\quad 2018$

Version:

Please cite the original version:

Dzolic, Z., Beyeh, N. K., Cetina, M., Turunen, L., \& Rissanen, K. (2018). Self-

Complementary Dimers of Oxalamide-Functionalized Resorcinarene

Tetrabenzoxazines. Chemistry: An Asian Journal, 13(2), 164-169.

https://doi.org/10.1002/asia.201701426

All material supplied via JYX is protected by copyright and other intellectual property rights, and duplication or sale of all or part of any of the repository collections is not permitted, except that material may be duplicated by you for your research use or educational purposes in electronic or print form. You must obtain permission for any other use. Electronic or print copies may not be offered, whether for sale or otherwise to anyone who is not an authorised user. 


\title{
Self-Complementary Dimers of Oxalamide-Functionalized Resorcinarene Tetrabenzoxazines
}

\author{
Zoran Džolić, ${ }^{[a]}$ Ngong Kodiah Beyeh, ${ }^{[b, c]}$ Mario Cetina,${ }^{[a, d]}$ Lotta Turunen, ${ }^{[a]}$ and Kari Rissanen ${ }^{*[a]}$
}

Dedication ((optional))

\begin{abstract}
Self-complementarity is a useful concept in supramolecular chemistry, molecular biology and polymeric systems. Two resorcinarene tetrabenzoxazines decorated with four oxalamide groups are synthesized and characterized. The oxalamide groups possessed self-complementary hydrogen bonding sites between the carbonyls and amide groups. The self-complementary nature of the oxalamide groups resulted in self-included dimeric assemblies. The hydrogen bonding interactions within the tetrabenzoxazines give rise to the formation of dimers, which are confirmed by single crystal Xray diffractions analysis and supported by NMR spectroscopy and mass spectrometry. The self-included dimers are connected by numerous and strong intermolecular $\mathrm{N}-\mathrm{H} \cdots \mathrm{O}$ and $\mathrm{C}-\mathrm{H} \cdots \mathrm{O}$ hydrogen bonds supplemented with $\mathrm{C}-\mathrm{H} \cdots \pi$ interactions, forming one-dimensional polymers, which are then further linked into threedimensional networks.
\end{abstract}

\section{Introduction}

The self-assembly of two or more geometrically and functionally complementary identical subunits held together by noncovalent interactions to form larger architectures on the molecular scale is a topic of high interest in Supramolecular Chemistry. ${ }^{[1-5]}$ This growing interest in the design of molecular systems with nanometer-sized assemblies based on self-assembly has resulted in very sophisticated molecular systems with application in various areas ranging from drug delivery and catalysis to molecular recognition and host-guest interactions. ${ }^{\left[{ }^{[6]}\right.}$ The design of structures utilizing the concept of self-complementarity spans over molecular biology and polymer science. Some examples include the pairing of DNA bases into double helix ${ }^{[10]}$ and the improved complementarity in polymer pairing systems. ${ }^{[11]}$

[a] Dr. Z. Džolić, Dr. M. Cetina, Acad. Prof. K. Rissanen University of Jyvaskyla, Department of Chemistry, Nanoscience Center, P.O.Box 35, 40014 Jyväskylä, Finland E-mail: kari.t.rissanen@jyu.fi

[b] Dr. N. K. Beyeh

Department of Applied Physics, School of Science Aalto University, Puumiehenkuja 2, 02150 Espoo, Finland

[c] Dr. N. K. Beyeh

University of Windsor, Department of Chemistry and Biochemistry, N9B 3P4 Windsor, ON, Canada

[d] Dr. M. Cetina

Department of Applied Chemistry, Faculty of Textile Technology University of Zagreb, Prilaz baruna Filipovića 28a, 10000 Zagreb, Croatia

Experimental details, Analytical methods, NMR, mass spectrometry and X-ray crystallographic data. Experimental details, Analytical methods, NMR, mass spectrometry and X-ray crystallographic data. CCDC 1577818 (7•TFA), 1577818 (1) and 1577820 (2).
Resorcinarenes are macrocyclic, bowl-shaped molecules when in the $C_{4 v}$ conformation. ${ }^{[12,13]}$ There are readily available and easily structurally modified, thus it is no surprise that these macrocyclic compounds have been extensively used for constructing supramolecular architectures like capsules, nanotubes and as receptors for a catalogue of different guests and substrates. ${ }^{[14-19]}$ Self-complementary hydrogen bonding donor and acceptor sites, properly positioned on a curved molecular platform, play key roles in the self-assembly of dimeric assemblies. However, the bowl-shaped nature when in the $C_{4 v}$ conformation and the relative rigidity of the resorcinarene skeleton, seems to make it harder to design the complementary and multiple hydrogen bonding donating and accepting groups on its upper rim. As such, only a few resorcinarene-based dimeric assemblies using simple amide or urea groups have been reported. ${ }^{[20-24]}$

As far as hydrogen bond mediated self-assembly systems are concerned, very little attention have been paid to the oxalamide derivatives, despite their high ability to participate in hydrogen bonding and rigid conformation. Indeed, oxalamide derivatives, due to their self-complementary hydrogen bonding interactions ability, have been used successfully in materials science, in protein engineering and for designing homo- and heterometallic complexes. ${ }^{[25-29]}$ Compared with the amide group, the oxalamide (-NH-CO-CO-NH-) group possesses elegant hydrogen-bond-forming capacity between $-\mathrm{C}=\mathrm{O}$ and $-\mathrm{NH}$ units. Moreover, the oxalamide group can provide one extra hydrogen bond with respect to the urea group, and thus may cause additional affinity in molecular recognition. The $N, N^{\prime}-$ disubstituted oxalamides exhibit two trans amide bonds, so that both $\mathrm{N}-\mathrm{H}$ bonds are oriented in a direction opposite to carbonyls and hence, are often involved in self-complementary bidirectional intermolecular hydrogen bonds.
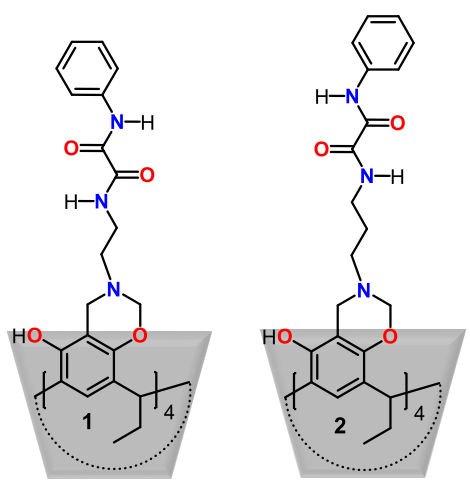

Figure 1.The chemical structures of $C_{4}$-symmetric oxalamide-functionalized resorcinarene tetrabenzoxazines 1 and $\mathbf{2}$.

Expanding our research activity in developing dimeric

For internal use, please do not delete. Submitted_Manuscript 
resorcinarene assemblies, we report here a new class of dimeric hydrogen-bond-mediated molecular assemblies based on the self-complementary oxalamide motif. We have synthesized two new resorcinarene tetrabenzoxazines $\mathbf{1}$ and $\mathbf{2}$ functionalized with oxalamido groups capable of self-complementary hydrogenbond interactions. The difference between upper rim arms in 1 and $\mathbf{2}$ originates from the number of aliphatic chain carbon atoms (Figure 1). Evidence for the existence of dimeric hydrogen bonded species was provided by a combination of single crystal X-ray diffraction, NMR spectroscopy and mass spectrometry.

\section{Results and Discussion}

\section{Synthesis}

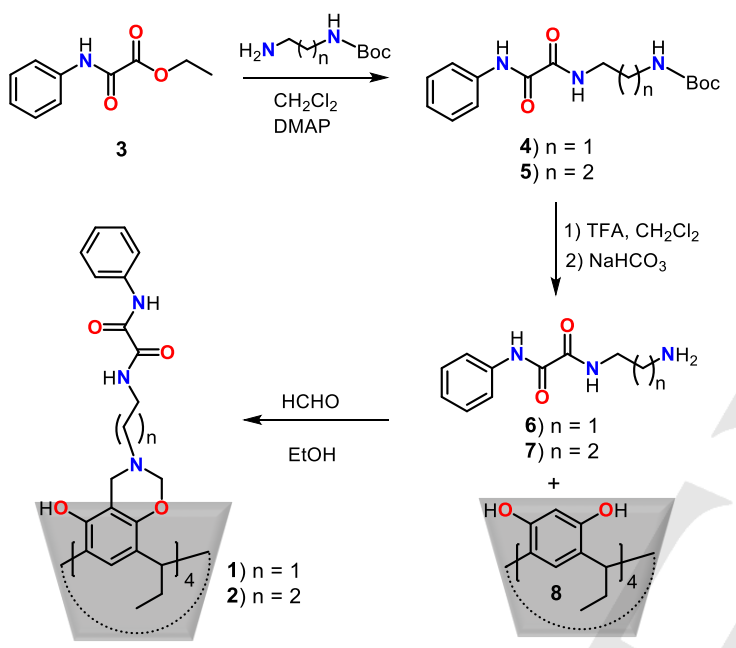

Scheme1.Synthesis of the (phenyl)oxalamide amines 6 and 7 , and the $C_{4}$ symmetric oxalamide-functionalized resorcinarene tetrabenzoxazines $\mathbf{1}$ and $\mathbf{2}$.

The oxalamide-functionalized resorcinarene tetrabenzoxazines 1 and $\mathbf{2}$ were synthesized from ethyl $\mathrm{N}$-(phenyl)oxalamate $3^{[30]}$ and mono-Boc-protected 1,2-diaminoethane or 1,3-diaminopropane, respectively. The ethyl $N$-(phenyl)oxalamate 3 was coupled with mono-Boc-protected diamines to give the diamides, which were then deprotected with trifluoroacetic acid (TFA) to give the amines as trifluoroacetate salts. Finally, Mannich condensation reaction between the amines and $C_{\text {ethyl }}$-resorcinarene 8 in the presence of excess formaldehyde afforded the oxalamidefunctionalized resorcinarene tetrabenzoxazines $\mathbf{1}$ and 2 (Scheme 1).

\section{NMR and Mass Spectrometry}

The room temperature ${ }^{1} \mathrm{H}$ NMR spectra of the oxalamidefunctionalized resorcinarene tetrabenzoxazines $\mathbf{1}$ and $\mathbf{2}$ are in complete agreement with the $C_{4}$ symmetrical structure. The absence of signals for the protons in 2-positions of the resorcinol rings indicates complete amino methylation. The presence of the signals between 3.3-5.0 ppm reveals the formation of the benzoxazine rings (Figures $2 \mathrm{a}$ and $\mathrm{S} 1 \mathrm{a}$ ). The ${ }^{1} \mathrm{H}$ NMR spectra of 1 in DMSO- $d_{6}$ and $\mathrm{CDCl}_{3}$ show relatively sharp signals. On the other hand, remarkably broadened ${ }^{1} \mathrm{H}$ NMR signals of oxalamido $\mathrm{NH}$ protons and methylene protons connecting to the oxalamido moiety were observed in ${ }^{1} \mathrm{H}$ NMR spectrum of $\mathbf{2}$ in $\mathrm{CDCl}_{3}$ (Figure S2), suggesting the existence of multiple hydrogen bonding interactions. Through ${ }^{1} \mathrm{H}$ NMR spectroscopic dilution experiments in the range $1-50 \mathrm{mM}$ in $\mathrm{CDCl}_{3}$, we determined the self-association constants $(K)$ for the tetrabenzoxazines 1 and 2 to be $3 \mathrm{M}^{-1}$ and $25 \mathrm{M}^{-1}$, respectively (Figure S3, Supporting Information).

Variable temperature ${ }^{1} \mathrm{H}$ NMR experiments show different dynamic behavior of $\mathbf{1}$ and 2 . The broadening of the NMR signals of 1 , observed by lowering the temperature, is probably due to the restricted motion of these protons when forming aggregates (Figure S1). With the upper rim arms extension to tetrabenzoxazine 2, different results were obtained. Contrary to what was observed for $\mathbf{1}$, by lowering the temperature, the ${ }^{1} \mathrm{H}$ NMR spectra of 2 in $\mathrm{CDCl}_{3}$ become more complex. New signals in the $\mathrm{NH}$ and $\mathrm{CH}_{3}$ zones appeared and new broad signals in the area between 3 and 5 ppm were observed (Figure 2). The loss of symmetry is most probably caused by the dimerization process and would support the self-encapsulation of the oxalamide side chains through complementary hydrogen bonding between the oxalamide pairs.

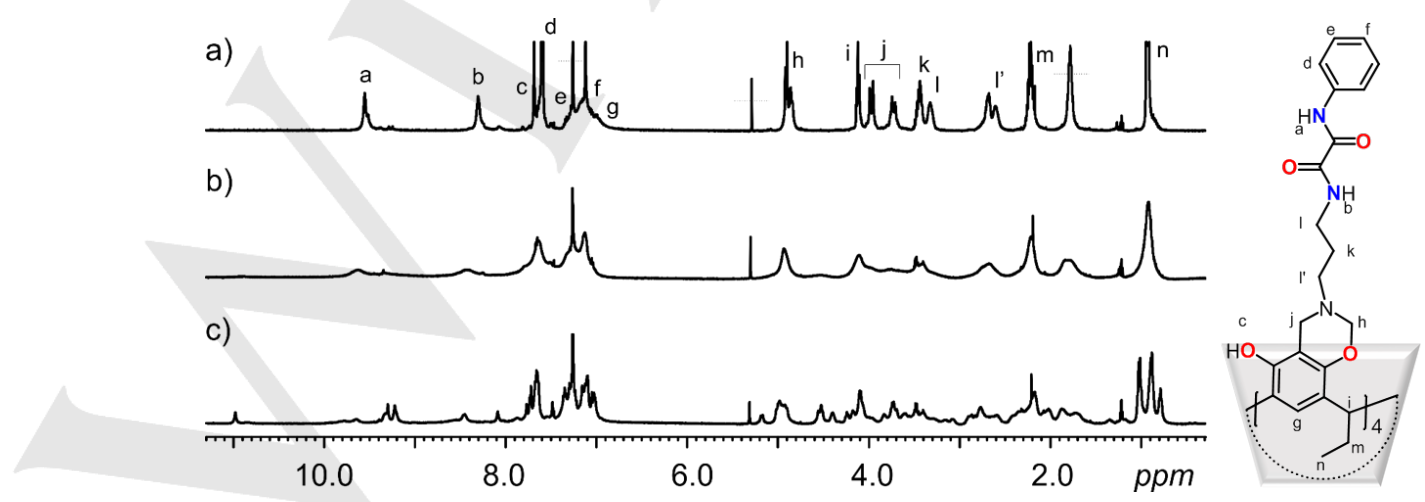

Figure 2. ${ }^{1} \mathrm{H}$ NMR spectra of 2 in $\mathrm{CDCl}_{3}$ at a) $303 \mathrm{~K}$, (b) $273 \mathrm{~K}$ and c) $243 \mathrm{~K}$.

For internal use, please do not delete. Submitted_Manuscript 


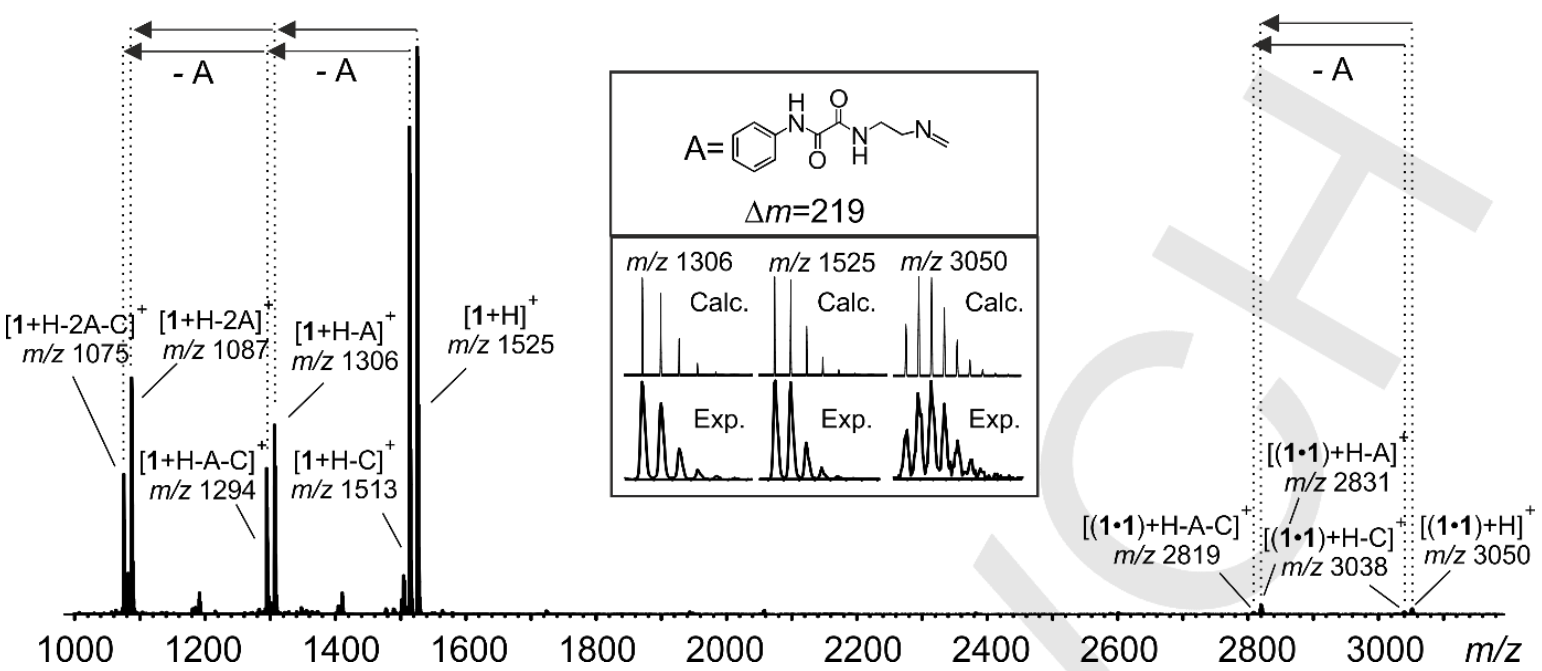

Figure 3. Positive ion ESI mass spectrum of compound 1. Signal for the protonated compound appears at $m / z 1525$ and for the dimeric assembly at $m / z 3050$. A series of consecutive fragments appear at equal distances of $\Delta m 219 \mathrm{Da}$ corresponding to the loss of an oxalamide arm through a retro-Diels-Alder elimination. Inset: The fragmented oxalamide arm, and experimental and calculated isotope patterns.

The stability and dimerization of the tetrabenzoxazines 1 and 2 were investigated in the gas phase through electrospray ionization mass spectrometry (ESI-MS) and MALDI-TOF MS, respectively. ${ }^{[31,32]}$ Taking compound 1 as an example, protonated ions $\left([1+\mathrm{H}]^{+}, \mathrm{m} / \mathrm{z} 1525\right)$ are formed and are presumably protonated at either one of the amide or amine nitrogens (Figure 3). The isotope patterns obtained by experiment agree well with those simulated on the basis of natural abundances. With an increase in sample cone voltage, intense peaks appear at repetitive distances of $\Delta m=219 \mathrm{Da}$ which corresponds to the loss of an oxalamide arm (A) in a retro-Diels-Alder ${ }^{[33,34]}$ reaction (for example, $\left([1+\mathrm{H}-\mathrm{A}]^{+}, \mathrm{m} / \mathrm{z} 1306\right)$. The elimination of up to two oxalamide arms was observed at higher voltages. Interestingly, ESI-MS analysis of 1 revealed higher mass species corresponding to the dimer. The spectrum has base peaks for the respective protonated monomer $\left([1+\mathrm{H}]^{+}, \mathrm{m} / \mathrm{z} 1525\right)$ and the corresponding molecular ions for the protonated dimer $\left([(\mathbf{1} \cdot \mathbf{1})+\mathrm{H}]^{+}, \mathrm{m} / \mathrm{z}\right.$ 3050) albeit with very low intensity (Figure 3$)$. The loss of an oxalamide arm was also observed from the dimer assembly $\left([(\mathbf{1} \cdot 1)+\mathrm{H}-\mathrm{A}]^{+}, m / z 2831\right)$. The measured isotope patterns of the signals are in good agreement with the calculated natural abundances, thus confirming the elemental compositions and the dimeric nature of the assemblies in the gas phase. The mass spectrum of compound 2 also shows peaks of consecutive fragments that appear at equal distances of $\Delta m 233 \mathrm{Da}$ corresponding to the loss of an oxalamide arm through a retro-Diels-Alder elimination from the dimeric species (Figure S4, Supporting Information).

\section{X-Ray Crystallography}

From the precursors of the tetrabenzoxazines $\mathbf{1}$ and $\mathbf{2}$, we succeeded in obtaining only single crystals of 7.TFA, which was used in the preparation of tetrabenzoxazine 2 . Indeed, in 7•TFA, one strong $\mathrm{N}-\mathrm{H} \cdots \mathrm{O}$ hydrogen bond, accompanied by one weaker $\mathrm{C}-\mathrm{H} \cdots \mathrm{O}$ hydrogen bond, links oxalamide groups of neighbouring ammonium cations, so forming head-to-tail dimers (Figure 4a). Not so surprisingly, cations and trifluoroacetate anions form $2+1$ trimers and $2+2$ tetramers by $\mathrm{N}-\mathrm{H} \cdots \mathrm{O}$ and $\mathrm{C}-$ $\mathrm{H} \cdots \mathrm{O}$ hydrogen bonds, some of them exhibiting strong chargeassisted hydrogen bonds (Figure $4 \mathrm{~b}$ and Figure $\mathrm{S} 5$ in Supporting Information).

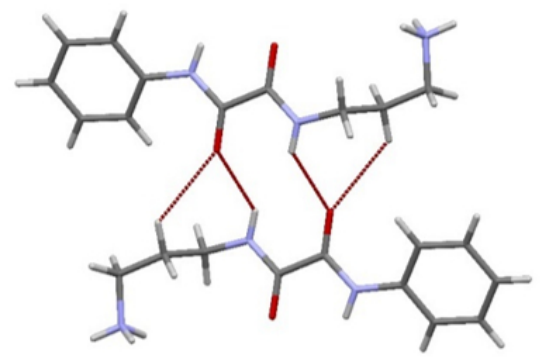

(a)

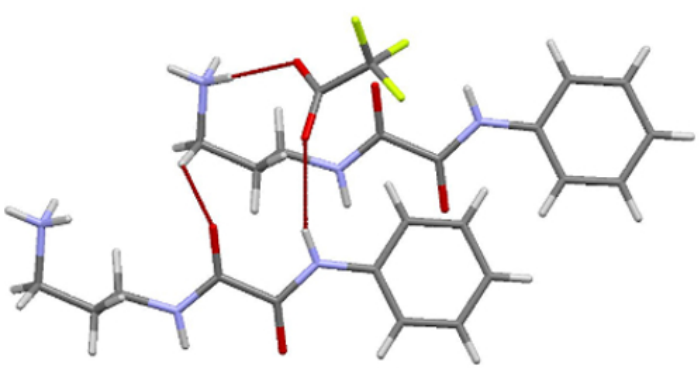

(b)

Figure 4. (a) Capped-stick representation of oxalamide ammonium cations of 7-TFA, showing formation of the head-to-tail dimer by $\mathrm{N}-\mathrm{H} \cdots \mathrm{O}$ and $\mathrm{C}-\mathrm{H} \cdots \mathrm{O}$ hydrogen bonds. (b) Capped-stick representation of a 2+1 trimer of 7-TFA consisting of two oxalamide-containing ammonium cations and one trifluoroacetate anion, and formed by $\mathrm{N}-\mathrm{H} \cdots \mathrm{O}$ and $\mathrm{C}-\mathrm{H} \cdots \mathrm{O}$ hydrogen bonds (for tetramers see SI, Figure S5). 
The crystal packing of 7•TFA along the a axis reveals that they are disposed in a herringbone fashion with the trifluoroacetate anions hydrogen-bonded to the oxalamide-containing ammonium cations (Figure 5). All above mentioned hydrogen bonds in 7.TFA, as well as one $\mathrm{C}-\mathrm{H} \cdots \pi$ interaction, form intricate array of interactions and two-dimensional network (Figure S6, Supporting Information).

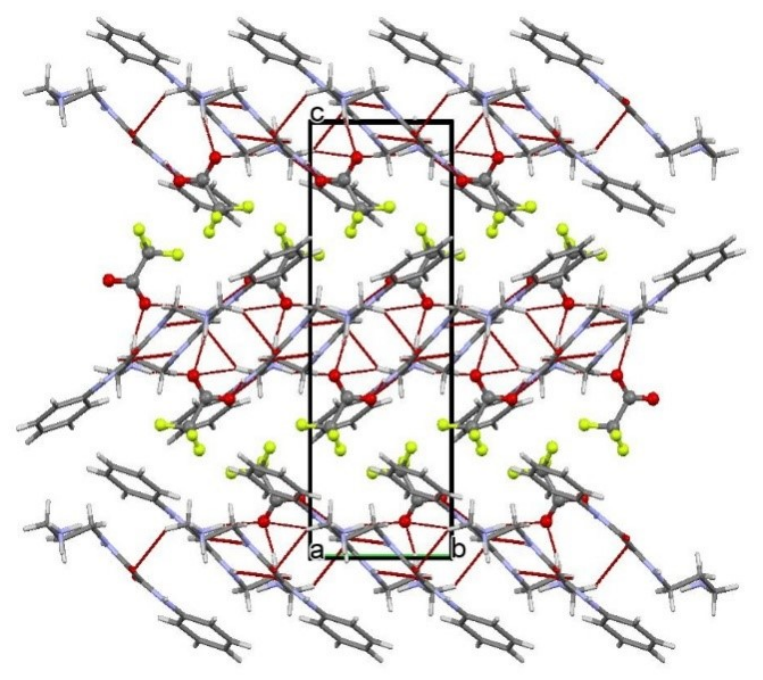

Figure 5. The packing of 7.TFA, viewed down the a axis. Oxalamide ammonium cations are shown by capped-stick representation, while trifluoroacetate anions in ball and stick style.

Slow evaporation of tetrabenzoxazines $\mathbf{1}$ and $\mathbf{2}$ solutions afforded colorless crystals, suitable for single-crystal X-ray analysis, although unstable when dried. The crystals of 1 were obtained by recrystallization from mixture of methanol and dichloromethane, and the crystal lattice contains also three dichloromethane and three methanol molecules, as well as some partial water molecules from recrystallization solvents. The crystal structure reveals a self-included dimeric structure formed by self-complementary $\mathrm{N}-\mathrm{H} \cdots \mathrm{O}$ hydrogen bonds between oxalamide groups, as well as one $\mathrm{N}-\mathrm{H} \cdots \mathrm{N}$ hydrogen bond (Figure 6 and Table S1, Supporting Information). The strongest $\mathrm{N}-\mathrm{H} \cdots \mathrm{O}$ interaction is formed between the two oxalamide groups of upper rim arms situated in the center of the dimer (Figure 6a). These three interactions are reinforced by two additional $\mathrm{C}-\mathrm{H} \cdots \mathrm{O}$ hydrogen bonds and four $\mathrm{C}-\mathrm{H} \cdots \pi$ interactions, so that, overall nine intermolecular interactions between the benzoxazine 1 molecules participate in the dimer formation. The capping oxalyl phenyl ring nicely resides in the tetrabenzoxazine cavity, so that inclusion of solvent molecules in the cavity is excluded. However, one methanol molecule is found to be situated between the dimers (Figure 6b), and is bound to the dimers by one $\mathrm{N}-\mathrm{H} \cdots \mathrm{O}$ and one $\mathrm{O}-\mathrm{H} \cdots \mathrm{O}$ hydrogen bond.

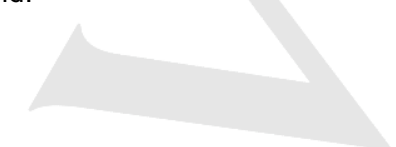

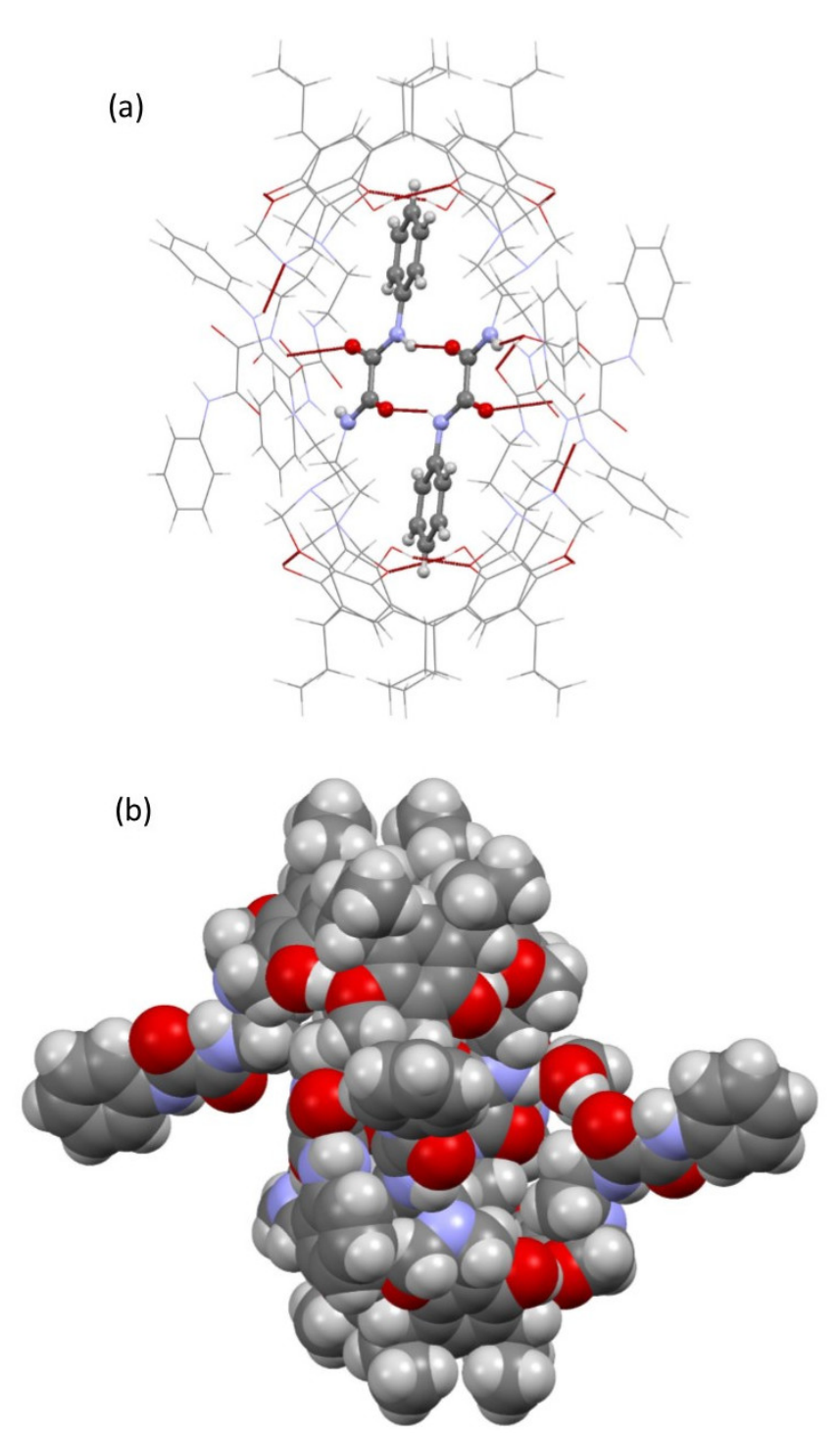

Figure 6. Wireframe representation (a) of the self-included dimer of $\mathbf{1}$, showing intermolecular $\mathrm{N}-\mathrm{H} \cdots \mathrm{O}$ and $\mathrm{N}-\mathrm{H} \cdots \mathrm{N}$ hydrogen bonds that form dimer. Atoms of self-included oxalamide moieties are presented in ball and stick style. CPK representation (b) of the self-included dimer of 1 .

Tetrabenzoxazine 2, which has three methylene groups in the oxalamide arm, crystallized also as a self-included dimer, but from two crystallographically independent molecules. This structure was obtained from a mixture of acetonitrile, methanol and chloroform and the crystal lattice contains also two chloroform molecules and one water molecule in the asymmetric unit. As in $\mathbf{1}$, the presence of water molecule could be a consequence of small amount of moisture present in the solvents used for recrystallization. Due to the presence of two crystallographically independent molecules of $\mathbf{2}$ in the asymmetric unit, extremely large number of intermolecular interactions participate in the dimer formation (Figure $7 \mathrm{a}$ and Table S1, Supporting Information). Hydrogen bonding is again largely dictated by the oxalamide groups, but when compared to

For internal use, please do not delete. Submitted_Manuscript 
1, the hydrogen bonds between oxalamide nitrogen and benzoxazine hydroxyl group oxygen atom is also observed. Thus, the dimer is formed by close to ten $\mathrm{N}-\mathrm{H} \cdots \mathrm{O}$ hydrogen bonds. One of three strongest $\mathrm{N}-\mathrm{H} \cdots \mathrm{O}$ interactions is formed between self-included arms, while the two others link the arms from the sides of the dimer to those in the center. All above mentioned $\mathrm{N}-\mathrm{H} \cdots \mathrm{O}$ interactions are accompanied by several $\mathrm{C}-\mathrm{H} \cdots \mathrm{O}$ hydrogen bonds and $\mathrm{C}-\mathrm{H} \cdots \pi$ interactions. Tight selfinclusion excludes any solvent molecules from the cavity and between the upper rim arms (Figure 7b).

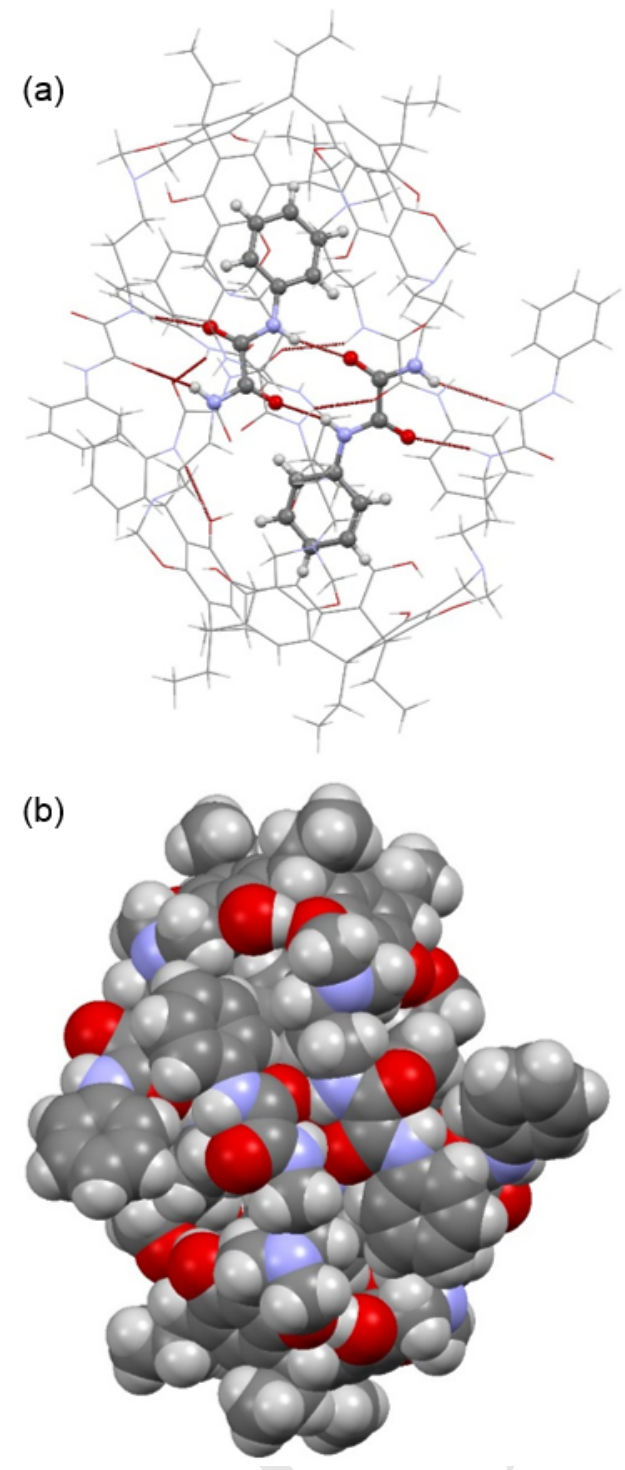

Figure 7. (a) Wireframe representation of the self-included dimer of 2 showing intermolecular $\mathrm{N}-\mathrm{H} \cdots \mathrm{O}$ hydrogen bonds that form dimer. Atoms of self-included oxalamide-containing moieties are presented in ball and stick style. (b) CPK representation of the self-included dimer of $\mathbf{2}$.

The Cambridge Structural Database $(C S D)^{[35]}$ search revealed that tetrabenzoxazines $\mathbf{1}$ and $\mathbf{2}$ are the first examples of structures comprising oxalamide group(s) and tetrabenzoxazine skeleton. Furthermore, to the best of our knowledge, there exist no structures of a resorcinarene tetrabenzoxazine containing long upper rim arms bonded to the benzoxazine nitrogen atom. The previous examples include short chain (hydroxyethyl group), ${ }^{[36]}$ different types of substituted rings, ${ }^{[24,37-42]}$ or unsubstituted ring bonded to the benzoxazine nitrogen atom via very short spacer. ${ }^{[43]}$ As in 1 , where upper rim arm snugly fits in the cavity of another tetrabenzoxazine molecule, yet the slightly elongated aliphatic oxalyl chain of $\mathbf{2}$ is twisted, as shown by the C50-C51-C52-N53 and C250-C251-C252-N253 torsion angles of $84.3(14)$ and $69.7(8)^{\circ}$. The corresponding torsion angle N64-C66-C67-N68 in the ethylene-oxalyl 1 is $137.5(6)^{\circ}$. Furthermore, the tetrabenzoxazine core in 1 is more open and unsymmetrical, the distances between nitrogen atoms of opposite benzoxazine rings being 9.12 and $12.09 \AA$ [distance difference $3.0 \AA$ ]. While in 2, distortion of tetrabenzoxazine core is smaller; the corresponding distances are 9.46 and 11.87 Åand 9.89 and $11.88 \AA$ [distance differences being 2.4 and $2.0 \AA$ ].

In 1 , self-included dimers are linked by two combinations of one $\mathrm{N}-\mathrm{H} \cdots \mathrm{O}$ hydrogen bond and one $\mathrm{C}-\mathrm{H} \cdots \mathrm{O}$ hydrogen bond into two chains (Figure S7, SI). These two hydrogen-bonded chains of dimers, mutually perpendicular to each other, generate two-dimensional network. All other $\mathrm{C}-\mathrm{H} \cdots \mathrm{O}$ hydrogen bonds, as well as $\mathrm{C}-\mathrm{H} \cdots \pi$ interactions extend two-dimensional network into a three-dimensional. Dichloromethane and methanol molecules as well as crystal lattice water are either hydrogen bonded to the dimers or fill the voids in the crystal lattice (Figure S8, Supporting Information). The same supramolecular motif, one-dimensional chain of hydrogen-bonded dimers formed by $\mathrm{N}-\mathrm{H} \cdots \mathrm{O}$ and $\mathrm{C}-\mathrm{H} \cdots \mathrm{O}$ hydrogen bonds was also observed in 2 (Figure S9, SI). The chains of dimers are further linked by numerous interactions, $\mathrm{C}-\mathrm{H} \cdots \mathrm{O}, \mathrm{C}-\mathrm{H} \cdots \mathrm{N}$, and $\mathrm{C}-\mathrm{H} \cdots \pi$, into a three-dimensional network (Figure S10, Supporting Information). Chloroform molecules are hydrogen-bonded to the dimers (Figure S11, Supporting Information), while water molecules fill free space in the crystal lattice.

\section{Conclusions}

In this work, we present the synthesis of two oxalamidefunctionalized resorcinarene tetrabenzoxazines. These tetrabenzoxazines feature extended self-complementary hydrogen bonding side arms (the oxalyl moieties) that lead to self-included dimeric structures. The hydrogen bonding between the dimer components is confirmed in the gas, liquid and solid phase via mass spectrometry, NMR spectroscopy and single crystal X-ray diffraction. The self-complementary oxalamide groups form strong hydrogen bonds between the carbonyl groups and the amide protons of the oxalyl groups leading to the formation of self-included dimers that extends into threedimensional polymeric networks in the solid state. Our results highlight the versatility of resorcinarenes and resorcinarene tetrabenzoxazines as very useful platforms for the construction of larger supramolecular architectures. Also, it emphasizes the self-complementary nature of the oxalamide groups which could 
be utilized in the design of receptors for specific target through hydrogen bonding.

\section{Experimental Section}

$C_{\text {Ethyr }}$ resorcinarene $\mathbf{8}$ was synthesized according to reported procedures. ${ }^{[44,45]}$ The reagents used in the synthesis were purchased from commercial sources (Sigma Aldrich) and are of analytical grade. All solvents were purified and dried by standard procedures and distilled prior to use. Melting points were determined on a Kofler hot-stage apparatus and are uncorrected. One- and two-dimensional NMR spectra were recorded on Bruker Avance DRX $500\left(500 \mathrm{MHz}\right.$ for ${ }^{1} \mathrm{H}$ and 126 $\mathrm{MHz}$ for ${ }^{13} \mathrm{C}$ ) spectrometer. Chemical shifts, in ppm, are referred to TMS as internal standard, $J$ values are given in $\mathrm{Hz}$. Data for the selfassociation constants were plotted as selected signal vs. total compound concentration and fitted by standard non-linear least square methods with a binding isotherm equation based on a 1:1 association model.

The mass spectrometric experiments were performed with a Micromass LCT Electrospray ionization-Time-of-flight instrument equipped with a Z geometry electrospray ion source and on microflex LT MALDI TOF mass spectrometer (Bruker Daltonik, Germany). For the experiment, the samples were introduced into the source as methanol solution mixtures at flow rates of $10 \mu \mathrm{l} / \mathrm{min}$, source temperature of $80^{\circ} \mathrm{C}$ and a desolvation temperature of $120^{\circ} \mathrm{C}$. Multiple scans were recorded and averaged for each spectrum in order to improve the signal-to-noise ratio.

Data for 7-TFA were collected at $120 \mathrm{~K}$ on Oxford Diffraction Xcalibur2 diffractometer with a Sapphire 3 CCD detector using graphitemonochromatized $\mathrm{MoK}_{\alpha}$ radiation $(\lambda=0.71073 \AA$ ). Data for 1 were collected at $173 \mathrm{~K}$ on a Bruker-Nonius Kappa Apex II diffractometer using graphite-monochromatized $\mathrm{MoK}_{\alpha}$ radiation $(\lambda=0.71073 \AA)$, while data for 2 were collected on the same instrument at $123 \mathrm{~K}$ using graphitemonochromatized $\mathrm{CuK}_{\alpha}$ radiation $(\lambda=1.54184 \AA$ ). All details about data collection and reduction, structure solution and refinement, as well as structure analysis and drawings preparation are given in Supporting Information. CCDC 1577818-1577820 contains the supplementary crystallographic data for this paper. These data can be obtained free of charge from The Cambridge Crystallographic Data Centre via www.ccdc.cam.ac.uk/data_request/cif.

\section{Acknowledgements}

The authors gratefully acknowledge financial support from the Academy of Finland (KR: grant nos. 265328, 263256 and 292746; NKB: grant no. 258653), University of Zagreb, Croatia, Aalto University, and the University of Jyvaskyla, Finland. This work was supported by the Academy of Finland through its Centres of Excellence Programme (HYBER 2014-2019).

Keywords: Supramolecular Chemistry • Dimer • Oxalamide, Resorcinarene $\cdot \mathrm{X}$-ray structure

[1] A. M. Castilla, W. J. Ramsay, J. R. Nitschke, Acc. Chem. Res. 2014, 47, 2063-2073.

[2] L. Adriaenssens, P. Ballester, Chem. Soc. Rev. 2013, 42, 3261-77.

[3] D. Ajami, J. Rebek, Acc. Chem. Res. 2013, 46, 990-999.

[4] Y. Inokuma, M. Kawano, M. Fujita, Nat. Chem. 2011, 3, 349-358.

[5] A. Szumna, Chem. Soc. Rev. 2010, 39, 4274-4285.
[6]

.

[19] N. K. Beyeh, M. Cetina, K. Rissanen, Cryst. Growth Des. 2012, 12, 4919-4926.

[20] M. Wierzbicki, A. Szumna, Chem. Commun. 2013, 49, 3860.

[21] Y. S. Park, J. Park, K. Paek, Chem. Commun. 2013, 49, 6316-8.

[22] Y. S. Park, S. Seo, E. H. Kim, K. Paek, Org. Lett. 2011, 13, 5904 5907.

[23] Y. S. Park, K. Paek, Org. Lett. 2008, 10, 4867-4870.

[24] J. L. Atwood, A. Szumna, J. Am. Chem. Soc. 2002, 124, 1064610647.

[25] M. Cametti, M. Cetina, Z. Džolić, Dalton Trans. 2015, 44, 72237229.

[26] D. Žilić, B. Rakvin, D. Milić, D. Pajić, I. Đilović, M. Cametti, Z. Džolić, Dalt. Trans. 2014, 43, 11877-11887.

[27] Z. Džolić, M. Cametti, D. Milić, M. Žinić, Chem. - A Eur. J. 2013, 19, 5411-5416.

[28] Z. Džolić, M. Cametti, A. Dalla Cort, L. Mandolini, M. Žinić, Chem. Commun. 2007, 3535-3537.

[29] Z. Džolić, K. Wolsperger, M. Žinić, New J. Chem. 2006, 30, 14111419.

[30] Y. A. Ibrahim, N. A. Al-Awadi, T. F. Al-Azemi, E. John, RSC Adv. 2014, 4, 38869.

[31] M. Przybylski, M. O. Glocker, ChemInform 2010, 27, no-no.

[32] C. A. Schalley, Mass Spectrom. Rev. 2002, 20, 253-309.

[33] B. Rickborn, in Org. React., John Wiley \& Sons, Inc., 1998.

[34] N. K. Beyeh, D. Fehér, M. Luostarinen, C. A. Schalley, K. Rissanen, J. Incl. Phenom. Macrocycl. Chem. 2006, 56, 381-394.

[35] F. H. Allen, Acta Crystallogr. Sect. B 2002, 58, 380-388.

[36] C. Schmidt, T. Straub, D. Falàbu, E. F. Paulus, E. Wegelius, E.

For internal use, please do not delete. Submitted_Manuscript 
Kolehmainen, V. Bohmer, K. Rissanen, W. Vogt, European J. Org Chem. 2000, 3937-3944.

[37] J. L. Atwood, A. Szumna, Chem. Commun. 2003, 940-941.

[38] L. Kröck, A. Shivanyuk, D. B. Goodin, J. Rebek, Chem. Commun. 2004, 272-3.

[39] K. Airola, V. Böhmer, E. F. Paulus, K. Rissanen, C. Schmidt, I. Thondorf, W. Vogt, Tetrahedron 1997, 53, 10709-10724.

[40] R. Arnecke, V. Boehmer, E. F. Paulus, W. Vogt, J. Am. Chem. Soc. $1995,117,3286-3287$.
M. T. El Gihani, H. Heaney, A. M. . Slawin, Tetrahedron Lett. 1995, 36, 4905-4908.

[42] P. Timmerman, W. Verboom, D. N. Reinhoudt, Tetrahedron 1996, 52, 2663-2704.

[43] H.-J. Schneider, U. Schneider, J. Incl. Phenom. Mol. Recognit. Chem. 1994, 19, 67-83.

For internal use, please do not delete. Submitted_Manuscript 
Entry for the Table of Contents (Please choose one layout)

\section{Layout 1:}

\section{FULL PAPER}

Text for Table of Contents

Two resorcinarene tetrabenzoxazines decorated with four oxalamide groups form self-complementary dimers through concerted hydrogen bonds between the carbonyl and amides groups of the oxalamide moieties. The self-complementary dimers are confirmed by single crystal X-ray diffractions analysis, NMR spectroscopy and mass spectrometry.

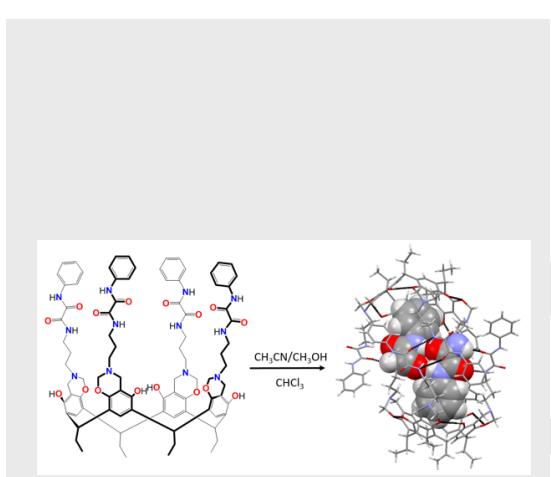

Zoran Džolić, Ngong Kodiah Beyeh, Mario Cetina and Kari Rissanen*

Page No. - Page No.

Self-Complementary Dimers of Oxalamide-

FunctionalizedResorcinarene

Tetrabenzoxazines

\section{Layout 2:}

\section{FULL PAPER}

((Insert TOC Graphic here; max. width: $11.5 \mathrm{~cm}$; max. height: $2.5 \mathrm{~cm})$ )
Author(s), Corresponding Author(s)*

Page No. - Page No.

Title

Text for Table of Contents

For internal use, please do not delete. Submitted_Manuscript 